\title{
Forglng New paths in Dlabetes PrevenTion (FINDIT): Study Protocol for a Randomized Controlled Trial
}

Jeffrey T. Kullgren ${ }^{1,2,3^{*}}$, Bradley Youles ${ }^{1}$, Shaina Shetty ${ }^{1}$, Caroline Richardson ${ }^{3,4}$, Angela Fagerlin ${ }^{5,6}$ and Michele Heisler ${ }^{1,2,3,7}$

\begin{abstract}
Background: Prediabetes is an asymptomatic condition in which patients' blood glucose levels are higher than normal but do not meet diagnostic criteria for type 2 diabetes mellitus (T2DM). A key window of opportunity to increase engagement of patients with prediabetes in strategies to prevent T2DM is when they are screened for T2DM and found to have prediabetes, yet the effects of this screening and brief counseling are unknown.
\end{abstract}

Methods: In this parallel-design randomized controlled trial we will recruit 315 non-diabetic patients from the Ann Arbor VA Medical Center (AAVA) who have one or major risk factors for T2DM and an upcoming primary care appointment at the AAVA, but have not had a hemoglobin A1c (HbA1c) test to screen for T2DM in the previous 12 months. After informed consent, participants will complete a baseline survey and be randomly assigned to, at the time of their next primary care appointment, one of two arms: (1) to have a hemoglobin A1c (HbA1c) test to screen for T2DM and receive brief, standardized counseling about these results or (2) to review a brochure about clinical preventive services. Participants will complete surveys 2 weeks, 3 months, and 12 months after their primary care appointment, and a weight measurement 12 months after their primary care appointment. The primary outcome is weight change after 12 months. The secondary outcomes are changes in perception of risk for T2DM; knowledge of T2DM prevention; self-efficacy and motivation to prevent T2DM; use of pharmacotherapy for T2DM prevention; physical activity; participation in weight management programs; and mental health. Quantitative analyses will compare outcomes among participants in the HbA1c test arm found to have prediabetes with participants in the brochure arm. Among participants in the HbA1c test arm found to have prediabetes we will conduct semi-structured interviews about their understanding of and reactions to receiving a prediabetes diagnosis.

Discussion: This trial will generate foundational data on the effects of a prediabetes diagnosis and brief counseling on patients' preventive behaviors and mediators of these behaviors that will enable the development of novel strategies to improve patient engagement in T2DM prevention.

Trial registration: ClinicalTrials.gov, NCT02747108. Registered on 18 April 2016.

Keywords: Diabetes prevention, Patient engagement, Screening, Patient education, Brief intervention

\footnotetext{
* Correspondence: jkullgre@med.umich.edu

${ }^{1}$ VA Center for Clinical Management Research, VA Ann Arbor Healthcare

System, PO Box 130170, Ann Arbor, MI 48113-0170, USA

2Department of Internal Medicine, University of Michigan Medical School,

Ann Arbor, MI, USA

Full list of author information is available at the end of the article
} 


\section{Background}

Prediabetes is an asymptomatic condition in which patients' blood glucose levels are higher than normal but not high enough to meet diagnostic criteria for type 2 diabetes mellitus (T2DM). The American Diabetes Association (ADA) defines prediabetes as either fasting plasma glucose of 100 to $125 \mathrm{mg} / \mathrm{dL}$, 2-hour plasma glucose of 140 to $199 \mathrm{mg} / \mathrm{dL}$ after a 75 -g oral glucose tolerance test, or hemoglobin A1c (HbA1c) of 5.7 to $6.4 \%$ [1]. Currently $38 \%$ of adults in the USA have prediabetes [2], which is associated with an approximately threefold greater annual incidence of T2DM [3] and an approximately 50\% greater risk of cardiovascular disease [4-6].

Fortunately, patients with prediabetes can significantly reduce their risk of developing T2DM through weight loss, physical activity, or pharmacotherapy [7, 8]. The landmark Diabetes Prevention Program (DPP) trial demonstrated that a lifestyle-modification program with the goals of at least $7 \%$ weight loss and at least 150 minutes of physical activity per week led to a 58\% reduction in the 3-year incidence of T2DM [9]. This was significantly greater than the $31 \%$ reduction in the incidence of T2DM that was observed among patients who received metformin $850 \mathrm{mg}$ by mouth twice daily, but progression to T2DM with metformin was still significantly less than the rate of progression in the control group. Due to the effectiveness [8] and cost-effectiveness [10] of these interventions, a number of studies have translated the DPP for use in different populations [11]. Moreover, the National DPP, an initiative led by the US Centers for Disease Control and Prevention, is currently working to disseminate and implement the DPP in communities across the USA [12].
Importance of patient engagement in diabetes prevention While there are defined ways to identify patients with prediabetes and evidence-based strategies to prevent or delay their progression to T2DM, the real-world execution of these strategies relies heavily on patient engagement. Specifically, in order for patients with prediabetes to engage in interventions to prevent or delay T2DM they must: (1) believe they have an elevated but modifiable risk of T2DM; (2) be motivated to prevent T2DM; (3) understand strategies they could use to prevent T2DM and be motivated to engage in these strategies; and (4) have the self-efficacy and support needed to sustain these behaviors. These goals are often difficult for at-risk patients to achieve, as evidenced by widespread lack of awareness of a prediabetes diagnosis, [13] frequent underestimation of risk of T2DM [14], and low rates of engagement in behaviors to prevent T2DM [15-17].

\section{Screening for diabetes as a window of opportunity for diabetes prevention}

A key opportunity to increase patients' engagement in evidence-based strategies to prevent T2DM is when they are informed at a primary care appointment that they have prediabetes. This process is depicted in the conceptual model shown in Fig. 1, which incorporates key domains from relevant health behavior theories such as the health belief model [18] and the transtheoretical model [19]. This process of informing patients that they have prediabetes usually starts with a screening laboratory test for T2DM. Patients whose laboratory test results are in the prediabetes range should then be informed by their provider that they have prediabetes and educated about how they can prevent or delay the onset of T2DM by: (1) losing weight and increasing physical activity, (2) participating in an evidence-based weight management

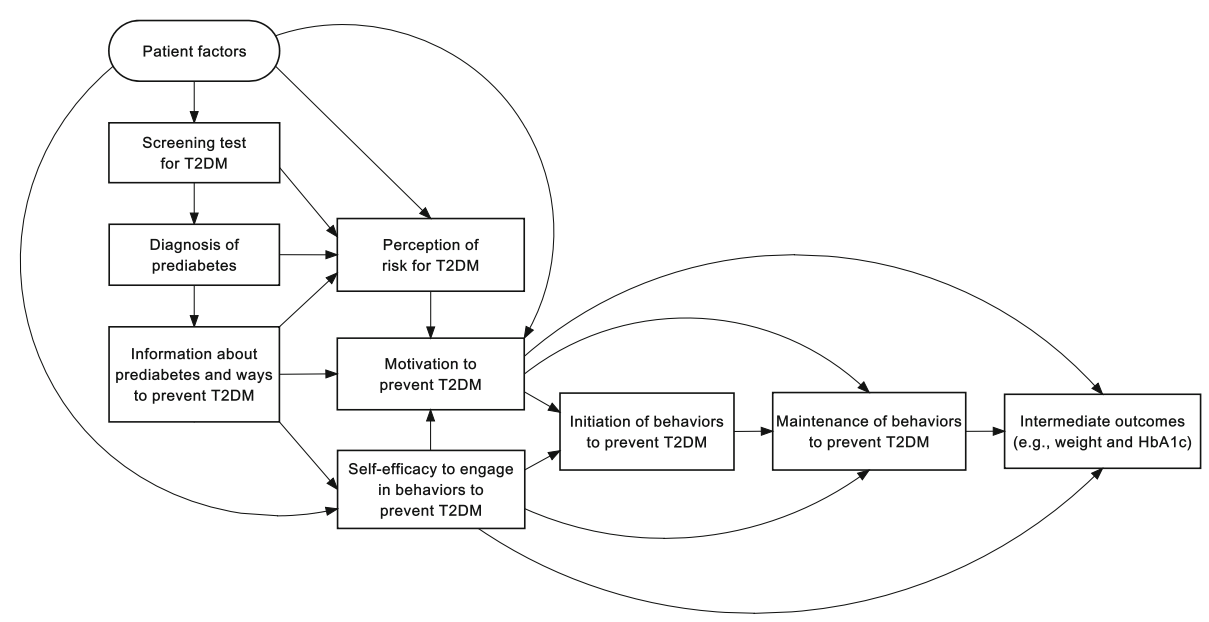

Fig. 1 Conceptual model of patient engagement in behaviors recommended for the prevention of type 2 diabetes mellitus (T2DM). HbA1C hemoglobin A1C 
program like the DPP; or (3) starting metformin [20]. At this critical stage, patients then should decide whether to engage in any behavior to reduce their risk for T2DM and, if so, which strategy or strategies to pursue.

Qualitative research from the UK suggests that this process of informing patients that they have prediabetes represents a highly "teachable moment" during which patients reflect on their risk of developing T2DM and form their motivation to reduce this risk [21, 22]. While this research indicates that the content of information given to patients when they are identified as having prediabetes is important, it also points to ways in which subtle factors may shape patient engagement. For example, the speed with which patients receive their screening test results, the source of those results (e.g., physician or ancillary provider), and the clarity of recommendations on behavior change may each impact the inferences patients draw about their risk of developing T2DM and their subsequent decisions to engage in behaviors to prevent T2DM [21, 22]. Despite the promise of this process of screening for T2DM to increase patients' perception of their risk of T2DM, their motivation and self-efficacy to prevent T2DM, and their efforts to modify risk factors for T2DM such as excess weight and lack of physical activity, the effects of a prediabetes diagnosis and brief counseling on these factors remain undefined [21, 23-25]. The objectives of this parallel-design randomized controlled trial (RCT) are to determine the effects of a prediabetes diagnosis and brief counseling on weight change; to examine the effects of a prediabetes diagnosis and brief counseling on engagement in behaviors to prevent T2DM and mediators of these behaviors; and to gain deep insights into patients' understanding of, and reactions to receiving, a prediabetes diagnosis.

Table 1 Inclusion and Exclusion Criteria

\section{Methods}

\section{Participants and recruitment}

We will recruit 315 non-diabetic patients from the Ann Arbor VA Medical Center (AAVA), who have an upcoming primary care appointment at the AAVA and one or more major risk factors for T2DM, but have not had an HbA1c test to screen for T2DM in the previous 12 months. The full inclusion and exclusion criteria are shown in Table 1.

Patients who meet preliminary eligibility criteria based on AAVA administrative data will be mailed a study information packet that describes the study and provides them with contact information to inquire further or opt out of being contacted about the study. After 10 days of mailing the letter, a Research Assistant who is blinded to the allocation sequence will call these preliminarily eligible patients to elicit their interest in study participation. For patients who are interested in participating, eligibility criteria that could not be assessed through AAVA administrative data will be evaluated through a brief set of additional screening questions. If at the end of this call the patient is eligible to participate, they will be asked to sign and return the informed consent form that had been mailed to them in their initial study information packet.

\section{Randomization and study arms}

After giving informed consent, the 315 enrolled patients will each complete a baseline survey. Then approximately 2 weeks before their primary care appointment, each patient will be randomly assigned to one of two study groups in a 4:1 ratio (252 to the HbA1c test and brief counseling arm and 63 to the clinical preventive brochure arm) using blocked randomization with variable block lengths. The allocation sequence will be determined using computer-generated random numbers
Exclusion Criteria

- Age $>75$ years $^{\mathrm{a}}$

- Type 1 diabetes ${ }^{\mathrm{a}, \mathrm{b}}$ (ICD-9 250 or ICD-10 E10.9)

- Type 2 diabetes ${ }^{\mathrm{a}, \mathrm{b}}$ (ICD-9 250 or ICD-10 E11)

- Dementia ${ }^{a}$ (ICD-9 290 or ICD-10 F03)

- End-stage renal disease ${ }^{\mathrm{a}, \mathrm{b}}$ (ICD-9 585.6 or ICD-10 N18.6)

- Severe chronic obstructive pulmonary disease (ICD-9 496 or ICD-10 J44) ${ }^{\mathrm{a}, \mathrm{b}}$

- Receiving chemotherapy ${ }^{\mathrm{b}}$

- New York Heart Association Class III or IV congestive heart failure (ICD-9 428 or ICD-10 I50.20 or ICD-10 150.30), b

- Pregnant or planning to become pregnant in the next year ${ }^{\mathrm{b}}$

- Stroke or myocardial infarction in the past 6 months ${ }^{b}$

- Cirrhosis (ICD-9 571 or ICD-10 K74.60) ${ }^{\text {a }}$

- HbA1c test in the past 12 months $^{a}$

${ }^{a}$ Data obtained from the VA Corporate Data Warehouse. ${ }^{b}$ Data obtained from a telephone screening survey administered to patients who are preliminarily eligible based on data from the VA Corporate Data Warehouse. HbA1c hemoglobin A1c 
and will be concealed in a password-protected file until study groups are assigned. We chose this 4:1 allocation ratio because in our main analyses we will compare patients in the HbA1c test and brief counseling arm, whose $\mathrm{HbA} 1 \mathrm{c}$ is in the prediabetes range to patients in the clinical preventive service brochure arm, and we anticipate that $20 \%$ of patients in the HbA1c test and brief counseling arm (i.e., 63 of 252 patients) will have HbA1c in the prediabetes range. All arm assignments will be communicated to patients by phone and a mailed letter, after which patients and Research Assistants will no longer be blinded to the arm assignment, but data analysts will continue to be blinded. Throughout the subsequent 12 months of the study patients in both arms will continue to receive usual care through their VA primary care team, which at the AAVA typically includes routine offers of a referral to the VA weight management program (MOVE) for patients who are overweight or obese.

\section{HbA1c test and brief counseling arm}

The 252 patients who are randomly assigned to the HbA1c test and brief counseling arm will be asked to have an HbA1c test to screen for T2DM at the AAVA outpatient laboratory. We will then interpret these HbA1c results and group them into the following categories based on American Diabetes Association (ADA) [26] and National DPP [12] guidelines:

- $\mathrm{HbA1c}<5.7 \%=$ normal (i.e., neither prediabetes nor T2DM)

- $\mathrm{HbA1c} \geq 5.7 \%$ and $<6.5 \%=$ prediabetes

- $\mathrm{HbA} 1 \mathrm{c} \geq 6.5 \%=\mathrm{T} 2 \mathrm{DM}$

These HbA1c results will be immediately communicated to and interpreted for each patient's VA primary care physician in a brief note in the VA Computerized Patient Record System (CPRS). Within 2 weeks of their primary care appointment, a Research Assistant will provide to the patient standardized brief phone counseling about their HbA1c result (Additional file 1), and will mail to the patient a summary of this standardized brief counseling (Additional file 2). These processes will provide patients and physicians with an opportunity to discuss the HbA1c result and make plans for follow-up information and support, yet will ensure that all patients will receive their HbA1c result within 2 weeks of the test, in accordance with VA standards.

In this standardized brief counseling and mailed information, patients whose $\mathrm{HbA1c}$ is in the normal range will simply be informed of this result. Patients whose HbA1c is in the prediabetes range will receive counseling and information based on the VA/Department of Defense guidelines for prevention of T2DM and will emphasize the risk of progression to T2DM and the rationale for preventive strategies, encourage aerobic exercise and a calorie-restricted diet to promote and maintain weight loss, set a goal of achieving and sustaining weight loss of at least $7 \%$ of body weight, and note pharmacotherapy as an option for preventing or delaying T2DM. Patients whose HbA1c is in the T2DM range will be told their HbA1c indicates they may have T2DM and will soon be contacted by their primary care team for follow up.

\section{Clinical preventive service brochure arm}

The 63 patients who are randomized to the clinical preventive service brochure arm will not have a screening HbA1c test ordered through the study. Instead, these patients will receive usual care and be mailed a brochure from the VA National Center for Health Promotion and Disease Prevention with general information about the value of clinical preventive services such as screenings and immunizations. These patients will be asked to review this information around the time of their primary care appointment. The brochure will be summarized for each patient's VA primary care physician in a brief VA CPRS note. Within 2 weeks of their primary care appointment, a Research Assistant will call the patient to provide standardized brief counseling based on the information in the brochure. In this way, patients in the clinical preventive service brochure arm will spend an approximately equal amount of time receiving and reviewing information related to prevention as patients randomized to the HbA1c test and brief counseling arm and will thus serve as an attention control group.

\section{Assessments \\ Surveys}

Patients will complete four surveys: (1) at baseline (i.e., before randomization); (2) within 2 weeks of receiving the HbA1c test results or the clinical preventive service brochure; (3) at 3 months after receiving the HbA1c test results or the clinical preventive service brochure; and (4) at 12 months after receiving the HbAlc test results or the clinical preventive service brochure (Fig. 2).

Patients will be able to complete and submit each survey online (via Qualtrics), by mail, in person, or by telephone. Data from mailed, in person, and telephone surveys will be entered into Qualtrics. The measures contained in each survey are shown in Table 2. For completion of each survey, patients will receive a US\$10 gift card. All survey data will be stored in password protected files on a secure server. 


\begin{tabular}{|c|c|c|c|c|c|c|}
\hline \multirow[b]{3}{*}{ TIMEPOINT } & \multicolumn{6}{|c|}{ STUDY PERIOD } \\
\hline & \multirow{2}{*}{$\begin{array}{c}\text { Enrolment } \\
-t_{I} \\
\end{array}$} & \multirow{2}{*}{$\begin{array}{c}\text { Allocation } \\
0\end{array}$} & \multicolumn{3}{|c|}{ Post-allocation } & \multirow{2}{*}{$\begin{array}{l}\text { Close-out } \\
12 \text { months }\end{array}$} \\
\hline & & & 2 weeks & 3 months & 6 months & \\
\hline \multicolumn{7}{|l|}{ ENROLLMENT: } \\
\hline Eligibility screen & $\mathrm{X}$ & & & & & \\
\hline Informed consent & $\mathrm{X}$ & & & & & \\
\hline Demographic characteristics & $\mathrm{X}$ & & & & & \\
\hline Allocation & & $\mathrm{X}$ & & & & \\
\hline \multicolumn{7}{|l|}{ INTERVENTIONS: } \\
\hline \multicolumn{7}{|l|}{$\begin{array}{r}\text { HbAlc Test and Brief Counseling } \\
\text { Arm }\end{array}$} \\
\hline \multicolumn{7}{|l|}{$\begin{array}{r}\text { Clinical Preventive Service Brochure } \\
\text { Arm } \\
\end{array}$} \\
\hline \multicolumn{7}{|l|}{ ASSESSMENTS: } \\
\hline Health literacy & $\mathrm{X}$ & & & & & \\
\hline $\begin{array}{r}\text { Patient activation, perception of risk } \\
\text { for T2DM, motivation to prevent } \\
\text { T2DM, knowledge of strategies to } \\
\text { prevent T2DM, self-efficacy to } \\
\text { engage in behaviors to prevent } \\
\text { T2DM }\end{array}$ & $X$ & & $X$ & $\mathrm{X}$ & & $\mathrm{X}$ \\
\hline $\begin{array}{r}\text { Physical activity, eating behaviors, } \\
\text { engagement in behaviors related to } \\
\text { T2DM prevention (attempting weight } \\
\text { loss, taking medication to prevent } \\
\text { T2DM, participating in a weight- } \\
\text { related wellness program) }\end{array}$ & $X$ & & & $\mathrm{X}$ & & $\mathrm{X}$ \\
\hline Mental health & & & & $X$ & & $X$ \\
\hline $\begin{array}{r}\text { Feelings about receiving a } \\
\text { prediabetes diagnosis, understanding } \\
\text { of prediabetes and behavioral } \\
\text { recommendations, facilitators of and } \\
\text { barriers to behavior change, and } \\
\text { uncertainties about having } \\
\text { prediabetes }\end{array}$ & & & & & $\mathrm{X}$ & \\
\hline Weight & $\mathrm{X}$ & & & & & $\mathrm{X}$ \\
\hline
\end{tabular}

Fig. 2 Schedule of enrollment, interventions, and assessments. T2DM type 2 diabetes mellitus, HbA1c hemoglobin A1C

Semi-structured interviews among patients with prediabetes To gain deeper understanding of patient perceptions of a prediabetes diagnosis and brief counseling, we will conduct semi-structured telephone interviews among a maximum variation purposive sample of patients who are newly diagnosed with prediabetes and have different levels of health literacy. We will focus on health literacy because of its strong relationship to patients' self-care behaviors, receipt of recommended preventive services, understanding of health information, and health outcomes [27]. We will conduct the interviews by phone to minimize participant burden and maximize the response rate. These participants will be invited to participate in the interview approximately 6 months after their HbA1c tests. Interviews will consist of open-ended questions to elicit feelings about receiving a prediabetes diagnosis, understanding of prediabetes and behavioral recommendations, facilitators of and barriers to behavior change, and uncertainties about having prediabetes. Each interview will be audio-recorded and transcribed verbatim, and we will stop conducting interviews when we reach thematic saturation. All interview data will be stored in password-protected files on a secure server.

\section{Outcomes}

The primary outcome is weight change 12 months after receipt of $\mathrm{HbA} 1 \mathrm{c}$ test results or the clinical preventive service brochure. The secondary outcomes will be changes in self-reported use of medication for prevention of T2DM, participation in a weight management program, perception of risk for T2DM, knowledge of strategies to prevent T2DM, motivation to prevent T2DM, self-efficacy to engage in behaviors to prevent 
Table 2 Measures

\begin{tabular}{|c|c|c|}
\hline Category & Source & Measures \\
\hline Demographic characteristics & VA administrative data at baseline & Age and gender \\
\hline Demographic characteristics & Baseline survey & Race/ethnicity and education \\
\hline Health literacy & Baseline survey & Chew health literacy scale \\
\hline Patient activation & All 4 surveys & Patient activation measure \\
\hline Perception of risk of T2DM & All 4 surveys & Adriaanse T2DM risk perception scale \\
\hline Motivation to prevent T2DM & All 4 surveys & Treatment self-regulation questionnaire \\
\hline Knowledge of strategies to prevent T2DM & All 4 surveys & $\begin{array}{l}\text { Knowledge of whether weight loss, physical activity, and } \\
\text { pharmacotherapy can prevent T2DM }\end{array}$ \\
\hline $\begin{array}{l}\text { Self-efficacy to engage in behaviors to } \\
\text { prevent T2DM }\end{array}$ & All 4 surveys & $\begin{array}{l}\text { Perceived competence scale for weight loss, increasing } \\
\text { physical activity, taking medication }\end{array}$ \\
\hline Physical activity & Baseline, 3 month, 12 month surveys & Short form of the international physical activity questionnaire \\
\hline Eating behaviors & Baseline, 3 month, 12 month surveys & Three-factor eating questionnaire \\
\hline $\begin{array}{l}\text { Engagement in health behaviors related to } \\
\text { T2DM prevention }\end{array}$ & $\begin{array}{l}\text { Surveys at baseline, } 3 \text { months, } \\
12 \text { months }\end{array}$ & $\begin{array}{l}\text { (1) Attempting weight loss, (2) taking medication to prevent } \\
\text { T2DM, or (3) participating in a weight-related wellness program }\end{array}$ \\
\hline Mental health & Surveys at 3 and 12 months & Short form health survey (SF-12) \\
\hline Weight & $\begin{array}{l}\text { VA administrative data at baseline and } \\
12 \text { months }\end{array}$ & Weight in pounds \\
\hline
\end{tabular}

T2DM type 2 diabetes mellitus

T2DM, physical activity, and mental health. We will not measure progression from prediabetes to T2DM because participants in the clinical preventive service brochure arm will not have an HbA1c test as part of the study.

\section{Sample size calculation}

Our main comparisons of interest are between outcomes for patients who receive a prediabetes diagnosis in the HbA1c test and brief counseling arm and outcomes for patients in the clinical preventive service brochure arm. Using $\alpha$ of $0.05,56$ patients who receive a prediabetes diagnosis in the HbA1c test and brief counseling arm and 56 patients in the clinical preventive service brochure arm will provide $80 \%$ power to detect a statistically significant difference between a projected mean 12-month weight change of -9.9 pounds (assuming a standard deviation (SD) of 18.0 pounds) among patients in the HbA1c test and brief counseling arm who receive a prediabetes diagnosis (comparable to mean 12-month weight change and its SD among 387 Veterans who were referred to a weight loss program in a recent clinical demonstration project at three VA medical centers [28, 29]) and a projected mean 12-month weight change of -1.4 pounds (assuming a SD of 13.5 pounds) in the clinical preventive service brochure arm (estimated from a random sample of VA patients who meet our inclusion criteria). In order to account for up to $12.5 \%$ dropout at 12 months [30] we will inflate our goal sample size for each of these groups to 63 patients.

Based on local VA data, we conservatively estimate that $25 \%$ of patients who meet our inclusion criteria will have HbAlc in the prediabetes range. Thus, to achieve our target of 63 patients with prediabetes in the HbA1c test and brief counseling arm and 63 patients in the clinical preventive service brochure arm, we will need to use a 4:1 allocation scheme to randomize 252 patients to the HbA1c test and brief counseling arm and 63 patients to the clinical preventive service brochure arm, for a total sample size of 315 patients.

\section{Statistical analyses \\ Quantitative analyses}

For the primary outcome analysis, we will use the twosample $t$ test to evaluate the difference in weight change between patients who are found to have prediabetes in the $\mathrm{HbA1c}$ test and brief counseling arm and patients in the clinical preventive service brochure arm who did not receive an HbA1c test through the study. Additionally, we will compare baseline measures (e.g., age and body mass index (BMI)) in these two groups. If we find imbalance in a baseline measure (defined as $P<0.10$ from the $F$ or $X^{2}$ test), we will adjust for this measure in analyses of 12-month weight change using a mixed-effects model for longitudinal data rather than the two-sample $t$ test. We will assess the extent of missing 12-month weight data and based on this assessment will consider using multiple imputation for missing data for this outcome. For secondary outcomes, we will use data from the baseline, 2-week, 3-month, and 12-month surveys to estimate mixed-effects regression models that will model mean changes between patients who are found to have prediabetes in the HbAlc 
test and brief counseling arm and patients in the clinical preventive service brochure arm.

\section{Qualitative analyses}

We will code semi-structured interview transcripts using a template analysis approach based on our conceptual model (Fig. 1) [31]. Three study team members will independently review a subset of transcripts using modified grounded theory to identify salient themes [31]. These investigators will discuss the themes, refine them, and achieve consensus on codes and definitions. Two study team members will then independently code transcripts in NVivo software. First, they will independently code the same $20 \%$ subset of the transcripts. The unweighted Cohen's kappa statistic will then be calculated for each response and averaged to provide a single index of inter-rater reliability. Once excellent agreement is achieved, these two study team members will divide the remaining interview transcripts evenly and code these transcripts separately. The full study team will meet regularly to discuss code summaries and memos, a group consensus approach that increases the rigor of data interpretation and allows documentation of sound evidence for findings [32].

\section{Discussion}

Nearly one in four VA patients has T2DM [33], which is a leading cause of blindness, amputations, and end-stage renal disease among Veterans and is associated with a twofold increase in annual mortality rates. Similarly, cardiovascular events resulting from T2DM and its associated risk factors lead to substantial morbidity and premature mortality among Veterans. In addition to these detrimental impacts of T2DM on the health of Veterans, these conditions contribute substantial costs within the VHA [34].

One important opportunity to limit these burdens is to facilitate patients' engagement in efforts to prevent T2DM by informing them they have prediabetes and providing brief counseling with evidence-based recommendations. Such brief interventions have in other clinical settings effectively targeted a range of behavioral risk factors for chronic disease like cigarette smoking, alcohol misuse, and illicit drug use [35-41]. In primary care clinics, these types of interventions have also shown promise in promoting physical activity [42] and healthy dietary practices $[43,44]$. A recent systematic review of brief interventions to promote physical activity and healthy dietary practices for the US Preventive Services Task Force found a positive correlation between the intensity and efficacy of these interventions, yet concluded that many higher-intensity interventions would be infeasible to implement in primary care settings [45]. Further, few lower-intensity interventions have targeted high-risk populations or leveraged behavioral science insights. Irrespective of their intensity, studies of brief interventions have also rarely reported objectively measured intermediate outcomes in addition to self-reported behaviors. As a result, the review concluded that "more trials are needed to evaluate low-intensity counseling interventions that could be more readily implemented in primary care" and that such trials should "collect and report objectively measured physiologic outcomes" [45].

In conclusion, an essential step in designing effective strategies to improve patient engagement in behavior change is to better understand their current levels of engagement in these behaviors and determine which factors influence their engagement. This RCT (SPIRIT Checklist included as Additional file 3) will generate foundational data on the effects of a prediabetes diagnosis and brief counseling on patients' preventive behaviors and mediators of these behaviors. Our future dissemination of these results in conference proceedings and peer-reviewed publications will enable the development of novel strategies to improve patient engagement in T2DM prevention.

\section{Trial status}

The FINDIT study began to recruit patients in December 2015.

\section{Additional files}

Additional file 1: Standardized brief phone counseling. (DOCX 65 kb) Additional file 2: Mailed information about $\mathrm{HbA} 1 \mathrm{c}$ results. (DOCX 16 kb) Additional file 3: SPIRIT checklist. (DOC $113 \mathrm{~kb}$ )

\section{Abbreviations}

AAVA: Ann Arbor VA Medical Center; ADA: American Diabetes Association; BMl: Body mass index; CPRS: Computerized Patient Record System; DPP: Diabetes Prevention Program; FINDIT: Forging new paths in diabetes prevention; HbA1c: Hemoglobin A1c; MOVE: Motivating Obese Veterans Everywhere; RCT: Randomized controlled trial; SD: Standard deviation; T2DM: Type 2 diabetes mellitus; US: United States; VA: Veterans Affairs; VHA: Veterans Health Administration

\section{Acknowledgements}

The authors thank Jane Wong, Nicholas Vogler, Keosha Corder, Kathy Swalwell, and Shannon Lohman for their assistance with recruitment, data collection, and study administration.

\section{Funding}

This study is funded by US Department of Veterans Affairs Health Services Research \& Development Career Development Award 13-267. The funder had no role in the design of the study and collection, analysis and interpretation of data, and no role in writing the manuscript. The views expressed in this article are those of the authors and do not necessarily reflect the position or policy of the Department of Veterans Affairs or the United States government.

\section{Availability of data and materials}

The datasets used and analyzed during the current study are available from the corresponding author on reasonable request. 


\section{Authors' contributions}

JTK, BY, SS, CR, AF, and MH substantially contributed to the study design. JTK drafted the manuscript, and all authors have critically evaluated it. All authors read and approved the final manuscript.

\section{Competing interests}

Dr. Kullgren has received consulting fees from SeeChange Health and HealthMine. No other authors have any competing interests.

\section{Consent for publication}

Not applicable.

\section{Ethics approval and consent to participate}

The study was approved by the Institutional Review Board of the VA Ann Arbor Healthcare System, Ann Arbor, MI, USA (\#2015-090699). Written informed consent to participate in the study will be obtained from all participants.

\section{Publisher's Note}

Springer Nature remains neutral with regard to jurisdictional claims in published maps and institutional affiliations.

\section{Author details}

'VA Center for Clinical Management Research, VA Ann Arbor Healthcare System, PO Box 130170, Ann Arbor, Ml 48113-0170, USA. ²Department of Internal Medicine, University of Michigan Medical School, Ann Arbor, MI, USA. ${ }^{3}$ University of Michigan Institute for Healthcare Policy and Innovation, Ann Arbor, MI, USA. ${ }^{4}$ Department of Family Medicine, University of Michigan Medical School, Ann Arbor, MI, USA. ${ }^{5}$ Salt Lake City VA Medical Center, Salt Lake City, UT, USA. 'Department of Population Health Studies, University of Utah, Salt Lake City, UT, USA. ${ }^{7}$ Department of Health Behavior and Health Education, University of Michigan, Ann Arbor, MI, USA.

Received: 17 November 2016 Accepted: 8 March 2017 Published online: 08 April 2017

\section{References}

1. American Diabetes Association. Standards of Medical Care in Diabetes-2017: Summary of Revisions. Diabetes Care. 2017;40(Suppl 1):S4-5.

2. Menke A, Casagrande S, Geiss L, Cowie CC. Prevalence of and trends in diabetes among adults in the United States, 1988-2012. JAMA. 2015;314:1021-9.

3. Zhang X, Gregg EW, Williamson DF, Barker LE, Thomas W, Bullard KM, et al. A1C level and future risk of diabetes: a systematic review. Diabetes Care. 2010:33:1665-73

4. Levitan EB, Song Y, Ford ES, Liu S. Is nondiabetic hyperglycemia a risk factor for cardiovascular disease? A meta-analysis of prospective studies. Arch Intern Med. 2004;164:2147-55.

5. Grundy SM. Pre-diabetes, metabolic syndrome, and cardiovascular risk. J Am Coll Cardiol. 2012;59:635-43.

6. Selvin E, Steffes MW, Zhu H, Matsushita K, Wagenknecht L, Pankow J, et al. Glycated hemoglobin, diabetes, and cardiovascular risk in nondiabetic adults. N Engl J Med. 2010;362:800-11.

7. Tuomilehto J, Lindström J, Eriksson JG, Valle TT, Hämäläinen H, llanneParikka $P$, et al. Prevention of type 2 diabetes mellitus by changes in lifestyle among subjects with impaired glucose tolerance. N Engl J Med. 2001;344:1343-50

8. Diabetes Prevention Program Research Group. 10-year follow-up of diabetes incidence and weight loss in the Diabetes Prevention Program Outcomes Study. Lancet. 2009:374:1677-86.

9. Knowler WC, Barrett-Connor E, Fowler SE, Hamman RF, Lachin JM, Walker $E A$, et al. Reduction in the incidence of type 2 diabetes with lifestyle intervention or metformin. N Engl J Med. 2002;346:393-403.

10. Group TDPPR. The 10-year cost-effectiveness of lifestyle intervention or metformin for diabetes prevention: an intent-to-treat analysis of the DPP/ DPPOS. Diabetes Care. 2012;35:723-30.

11. Kramer MK, Kriska AM, Venditti EM, Miller RG, Brooks MM, Burke LE, et al. Translating the diabetes prevention program: a comprehensive model for prevention training and program delivery. Am J Prev Med. 2009;37:505-11.

12. Albright AL, Gregg EW. Preventing type 2 diabetes in communities across the U.S.: the National Diabetes Prevention Program. Am J Prev Med. 2013:44(4 Supplement 4):S346-51
13. US Centers for Disease Control and Prevention. Awareness of prediabetes United States, 2005-2010. MMWR Morb Mortal Wkly Rep. 2013;62:209-12.

14. Adriaanse MC, Twisk JWR, Dekker JM, Spijkerman AMW, Nijpels G, Heine RJ, et al. Perceptions of risk in adults with a low or high risk profile of developing type 2 diabetes; a cross-sectional population-based study. Patient Educ Couns. 2008;73:307-12.

15. Yang K, Lee Y-S, Chasens ER. Outcomes of health care providers' recommendations for healthy lifestyle among U.S. adults with prediabetes. Metab Syndr Relat Disord. 2011;9:231-7.

16. Okosun IS, Lyn R. Prediabetes awareness, healthcare provider's advice, and lifestyle changes in American adults. Int J Diabetes Mellit. 2010;3:11-18. doi: 10.1016/j.jjdm.2010.12.001.

17. Ruge $T$, Nyström L, Lindahl B, Hallmans G, Norberg M, Weinehall $L$, et al Recruiting high-risk individuals to a diabetes prevention program: how hard can it be? Diabetes Care. 2007:30:e61.

18. Glanz K, Marcus Lewis S, Vishwanath K. Health Behavior and Health Education: Theory, Research, and Practice. 4th ed. San Francisco: John Wiley \& Sons, Inc.; 2008

19. Prochaska JO, Redding CA, Evers KE. The transtheoretical model and stages of change. In: Health behavior and health education: theory, research, and practice. 4th ed. San Francisco: John Wiley \& Sons, Inc; 2008. p. 97-121.

20. $\mathrm{Va} / \mathrm{DoD}$ clinical practice guideline for the management of diabetes mellitus. 2010. http://www.healthquality.va.gov/guidelines/CD/diabetes/. Accessed 13 Mar 2013.

21. Troughton J, Jarvis J, Skinner C, Robertson N, Khunti K, Davies M. Waiting for diabetes: perceptions of people with pre-diabetes: a qualitative study. Patient Educ Couns. 2008;72:88-93.

22. Adriaanse MC, Snoek FJ, Dekker JM, Spijkerman AMW, Nijpels G, Van Der Ploeg HM, et al. Perceived risk for type 2 diabetes in participants in a stepwise population-screening programme. Diabet Med. 2003:20:210-5.

23. Eborall H, Davies R, Kinmonth A-L, Griffin S, Lawton J. Patients' experiences of screening for type 2 diabetes: prospective qualitative study embedded in the ADDITION (Cambridge) randomised controlled trial. BMJ. 2007;335:490.

24. Eborall HC, Griffin SJ, Prevost AT, Kinmonth A-L, French DP, Sutton S. Psychological impact of screening for type 2 diabetes: controlled trial and comparative study embedded in the ADDITION (Cambridge) randomised controlled trial. BMJ. 2007;335:486.

25. Mezuk B, Johnson-Lawrence $\mathrm{V}$, Lee H, Rafferty JA, Abdou CM, Uzogara EE, et al. Is ignorance bliss? Depression, antidepressants, and the diagnosis of prediabetes and type 2 diabetes. Health Psychol. 2013;32:254-63.

26. American Diabetes Association. Standards of medical care in diabetes-2014. Diabetes Care. 2014;37(Supplement_1):S14-80.

27. Berkman ND, Sheridan SL, Donahue KE, Halpern DJ, Crotty K. Low health literacy and health outcomes: an updated systematic review. Ann Intern Med. 2011:155:97-107.

28. Damschroder LJ, Moin T, Datta SK, Reardon CM, Steinle N, Weinreb J, et al. Implementation and evaluation of the VA DPP clinical demonstration: protocol for a multi-site non-randomized hybrid effectivenessimplementation type III trial. Implement Sci. 2015;10:68.

29. Moin T, Damschroder L, AuYoung M, Maciejewski ML, Datta SK, Weinreb JE, et al. Diabetes Prevention Program translation in the Veterans Health Administration. Am J Prev Med. 2017. doi:10.1016/j.amepre.2016.11.009. [Epub ahead of print].

30. Lutes LD, DiNatale E, Goodrich DE, Ronis DL, Gillon L, Kirsh S, et al. A randomized trial of a small changes approach for weight loss in veterans: design, rationale, and baseline characteristics of the ASPIRE-VA trial. Contemp Clin Trials. 2013;34:161-72.

31. Crabtree BF, Miller WL. Doing qualitative research. Thousand Oaks: SAGE; 1999.

32. Sandelowski M, Barroso J. Writing the proposal for a qualitative research methodology project. Qual Health Res. 2003;13:781-820.

33. Diabetes QUERI fact sheet. 2012. http://www.queri.research.va.gov/about/ factsheets/dm_factsheet.pdf. Accessed 6 Jan 2013

34. Maciejewski ML, Maynard C. Diabetes-related utilization and costs for inpatient and outpatient services in the Veterans Administration. Diabetes Care. 2004:27 suppl 2:b69-73.

35. Stead LF, Bergson G, Lancaster T. Physician advice for smoking cessation. Cochrane Database Syst Rev. 2008:5:CD000165.

36. Sinadinovic K, Wennberg P, Berman AH. Internet-based screening and brief intervention for illicit drug users: a randomized controlled trial with 12month follow-up. J Stud Alcohol Drugs. 2014;75:313. 
37. Bernstein E, Edwards E, Dorfman D, Heeren T, Bliss C, Bernstein J. Screening and brief intervention to reduce marijuana use among youth and young adults in a Pediatric Emergency Department. Acad Emerg Med Off J Soc Acad Emerg Med. 2009;16:1174-85.

38. Marlatt GA, Baer JS, Kivlahan DR, Dimeff LA, Larimer ME, Quigley LA, et al. Screening and brief intervention for high-risk college student drinkers: results from a 2-year follow-up assessment. J Consult Clin Psychol. 1998;66:604-15.

39. Curry SJ, Ludman EJ, Grothaus LC, Donovan D, Kim E. A randomized trial of a brief primary-care based intervention for reducing at-risk drinking practices. Health Psychol. 2003;22:156-65.

40. Whitlock EP, Polen MR, Green CA, Orleans T, Klein J. Behavioral counseling interventions in primary care to reduce risky/harmful alcohol use by adults: a summary of the evidence for the U.S. preventive services task force. Ann Intern Med. 2004;140:557-68.

41. Chang G, McNamara TK, Orav EJ, Koby D, Lavigne A, Ludman B, et al. Brief intervention for prenatal alcohol use: a randomized trial. Obstet Gynecol. 2005;105(5 Pt 1):991-8.

42. Orrow G, Kinmonth A-L, Sanderson S, Sutton S. Effectiveness of physical activity promotion based in primary care: systematic review and metaanalysis of randomised controlled trials. BMJ. 2012;344:e1389.

43. Steptoe A, Doherty S, Rink E, Kerry S, Kendrick T, Hilton S. Behavioural counselling in general practice for the promotion of healthy behaviour among adults at increased risk of coronary heart disease: randomised trial. BMJ. 1999;319:943-8.

44. Hardcastle SJ, Taylor AH, Bailey MP, Harley RA, Hagger MS. Effectiveness of a motivational interviewing intervention on weight loss, physical activity and cardiovascular disease risk factors: a randomised controlled trial with a 12month post-intervention follow-up. Int J Behav Nutr Phys Act. 2013;10:40.

45. Lin JS, O'Connor E, Whitlock EP, Beil TL. Behavioral counseling to promote physical activity and a healthful diet to prevent cardiovascular disease in adults: a systematic review for the U.S. Preventive Services Task Force. Ann Intern Med. 2010;153:736-50

\section{Submit your next manuscript to BioMed Central and we will help you at every step:}

- We accept pre-submission inquiries

- Our selector tool helps you to find the most relevant journal

- We provide round the clock customer support

- Convenient online submission

- Thorough peer review

- Inclusion in PubMed and all major indexing services

- Maximum visibility for your research

Submit your manuscript at www.biomedcentral.com/submit 